\title{
"Today Is So Cool Nobody Wants to Leave": What Makes Teenagers Engaged in Developing Educational Games at School?
}

\author{
Dyego Carlos Sales de Morais ${ }^{1}$, Taciana Pontual Falcão ${ }^{2}$ \\ ${ }^{1}$ Centro de Informática - Universidade Federal de Pernambuco - Recife, PE \\ ${ }^{2}$ Departamento de Estatística e Informática - Universidade Federal Rural de \\ Pernambuco - Recife, PE \\ moraisdcs@gmail.com, taciana.pontualeufrpe.br
}

\begin{abstract}
The current generation of young learners demands innovative educational approaches that meet their characteristics and needs. Recent initiatives go beyond the use of games and propose that students can construct games themselves, developing design and programming abilities, and learning curricular contents in more engaging ways. However, integrating digital games to formal educational settings involves several aspects related to the structure of educational systems and traditional methods of teaching. This research analyzes two school-based processes of game development and identifies aspects that promote student engagement. Results form the basis for modeling a process for game development in the educational context.
\end{abstract}

\section{Introduction}

The use of information and communication technologies in educational settings can produce benefits for the process of knowledge construction. This is increasingly true for the young generations of learners, called by some 'digital natives' [Prensky 2001], who have had access to digital technologies from birth. Their interaction with pervasive technological devices and their immersion in the digital world not only makes them familiar with technology, but affects the ways they think, express themselves, build knowledge, and engage with content [Mattar 2010, Prensky 2001]. It is thus important to understand their needs and adapt the educational system to enable a fruitful integration of digital technologies in formal learning processes and engage the students.

One of the recent ideas for reconnecting with the students comes from their interest in digital games. The use of games in educational processes has obtained positive results, mainly related to increased motivation and engagement [Wyeth et al. 2013]. However, introducing games in education will not work if done as an isolated action. Fredricks et al. (2004) highlight that students' engagement is very reactive to changes in the context - in this case, the school's social arrangements [Meira and Pinheiro 2012]. More than just playing a game, democratic spaces that enable autonomy, encouraging collaboration and active participation, are key for engaging learners. In this sense, some initiatives emerge that propose not only the use of games in education, but their construction by the students. They draw from Papert's original ideas on Constructionism [Papert and Harel 1991], now updated and enriched with the wide range of possibilities brought by current technologies, such as the easy access to 
programming through visual environments and different levels of software modification. As Blikstein (2015) declared during his keynote talk at the Brazilian Conference of Informatics in Education (CBIE), "the evidence of learning is what students do in practice" (our translation). Such projects of game development put students in touch with curricular contents, and programming and design abilities. Nevertheless, it does not constitute an easy process, and certainly not one to which students are habituated. Therefore, a lot of tuning is needed to find adequate forms of integrating activities of this nature to the school routine.

The present research analyzed two processes of digital games development by students, both based in school settings, with the goal of investigating which aspects of the processes and of the environment promote students' engagement. Results serve as important evidence and input for modeling an (engaging!) process of digital game development in schools, hopefully contributing to shaping the innovative environment of the schools of the near future. This article first presents some of the current research on engagement in educational processes. Next, we describe the settings where the research took place and explain the methodology for data collection and analysis. We then present the aspects found to promote engagement in settings of this nature, followed by the main challenges associated to the school context. We conclude by indicating how this feeds into future work.

\section{Engagement in Educational Processes}

Generally speaking, engagement refers to the decision of taking part in activities, and to the level of commitment involved in this decision [Lave and Wenger 1991]. In educational settings, engagement is fundamental for learning. Using digital games in learning processes is gaining popularity for its appeal to the young generations, and some researchers argue that having students themselves developing the games is even more engaging than when they just play them [Lim 2008]. There are indications of enhanced academic achievement and critical thinking [Yang and Chang 2013], development of logical thinking and problem-solving competencies [Vos et al. 2011]; student empowerment [Triantafyllakos et al. 2011]; and motivation and engagement [Robertson and Howells 2008; Von et al. 2011], in such activities. However, particularly regarding the scope of this article, analysis of engagement is mostly superficial and subject to the novelty effect bias. So, despite the argument that dealing with games (playing or building) is 'naturally' engaging for children and teenagers, deeper investigation of the nature and consequences of such engagement is needed.

Fredricks et al. (2004) present three dimensions of engagement in education: behavioral (conduct and level of participation in classroom and extracurricular activities, both academic and social); emotional (feelings towards the school, teachers and peers, which may create a sense of belonging to the school community); and cognitive (comprehension of the concepts involved in the activity; desire of learning and going beyond intellectual demands, sought for challenges, self-regulated learning). These three dimensions are clearly intertwined. We base our analysis on three aspects of engagement identified in the literature, related to Fredricks et al. (2004) dimensions, and congruent with our data: interest in participating, collaboration and autonomy. Interest in participating is the most direct indicator of engagement, deeply related to the common-sense definition of engagement per se, and to behavioural engagement [Fredricks et al. 2004]. Active participation in classroom activities can be seen as 
evidence of students' motivation and engagement in learning processes [Parsons and Taylor 2011]. Collaboration relates to emotional engagement [Fredricks et al. 2004] in the sense that relationships among peers and educators play an important role and can affect learning [Willekens and Gibson 2010]. A solidary and collectivist environment with minimal conflict encourages student's engagement and promotes better academic achievement [Sagayadevan and Jeyaraj 2012]. Collaborative activities that stimulate interaction among peers and educators, exchanging ideas and contributing with opinions and actions, are fundamental to create an engaging environment [Kanthan 2011]. Last but not least, autonomy is closely related to the cognitive dimension of engagement [Fredricks et al. 2004]. Autonomous students are able to conduct elements of their learning process, such as how to undertake a certain task [Parsons and Taylor 2011]. They seek information and resources for themselves in order to accomplish their activities [Kanthan 2011]. The feeling of being able and allowed to work autonomously develops students' intrinsic motivation to perform their activities [Zepke et al. 2010].

\section{Context and Methodology}

This research was performed in two settings with projects where middle school students develop digital games. The first setting is a public middle school that combines the traditional syllabus with classes on design and programming of digital games. Students must choose if they would like to have the role of designer or programmer as they enter the school. The educators define the themes and sometimes the briefing of the games. Depending on their expertise, students have more or less freedom to make decisions about the game mechanics and narrative. The games are developed during class time, with the support of the educators, in groups formed according to students' preferences. Students are encouraged to perform basic user centered research when the games involve specific populations (e.g. a project on diabetes). They are also encouraged to enter game development competitions like Global Game Jam. The aim of the school is that students will be able to follow a career in game development, and/or take related graduate courses like design or computer science.

The second setting is a public middle school where the DEMULTS project takes place since 2012. DEMULTS is a transdisciplinary research project which investigates the relationships between learning and technology within a process of development of educational digital games. Aiming at developing games that include curricular contents, but are more motivating for the students than the average games known as 'educational', DEMULTS adopts participatory design [Bødker et al. 1995] and end-user programming [Lieberman 2006], as students design and develop games whose target audience are themselves, their peers, and other students of similar profile. Learners are the leaders in the design of the games, with educators from the DEMULTS team as helpers. Students are divided in two groups in the beginning of the cycle, according to their preferences and abilities: designers and programmers. They have a few classes on developer tools and the basics of digital games (mechanics, characters, narrative, etc.), but the idea of the project is that they will learn in practice, with the help of the educators. Each DEMULTS cycle targets a specific school subject, and each team must choose a curricular item within that subject to address, and integrate it into the game narrative.

Data was collected through semi-structured interviews about the participatory processes for the development of digital games in high school and observation of the 
process in practice. In Setting 1, 10 hours of non-participant observation were performed in design and programming classes, and interviews were performed with four students and two educators. In Setting 2, participant observation was performed from August 2015 to July 2016 in one-and-a-half-hour meetings twice a week, at the school, as extra-curricular activities with 10 boys and 9 girls between 14 and 17 years old. Four students that participated in previous cycles of the project were interviewed. While in Setting 1 observations were exclusively performed by the first author of this paper, in Setting 2 the whole project team, which included the first author, collaborated with field notes from participant observation. This group included two university professors, one graduate student and four undergraduate students. Most of the data was collected in Setting 2 through participant observation. The interviews in both settings were performed for get other perceptions about the processes and artifacts. Qualitative analysis was performed to find out which aspects engage students in processes of development of digital games in school contexts. Content analysis of transcribed interviews and field notes was performed considering the three indicators of engagement selected from the literature: autonomy, collaboration and interest in participation.

\section{Aspects that Promote Engagement}

\subsection{Autonomy}

The possibility of working autonomously through a democratic social arrangement was found to be a necessary condition for processes of game development in schools, considering the characteristics of the current generation of learners. The aspects that promote autonomy are described next.

\subsubsection{Democratic choices}

Students should be able to make as many decisions as possible themselves. In both settings, engagement was higher when the games' themes, mechanics and narrative were defined by the students. In Setting 2, it is possible to have students choose the specific topic within a school subject, and/or the school subject itself. This can be done through discussion followed by voting, for example. Putting students in places of decision creates a democratic environment that helps moving away from the traditional educational model - where the teachers carry the exclusive responsibility of deciding the best ways for students to learn [Meira and Pinheiro 2012] - towards Vygotsky's sociointeractionism [Vygotsky 1989], according to which the school is a cultural locus for the subject's development.

\subsubsection{Prompting and challenges}

Another way of promoting socio-interactionism was identified in the analysis of the interaction between educators and students. Prompting students with follow-up questions on their own questions and posing challenges, while avoiding direct answers and orders, was a good method for increasing their autonomy. An example from the data that relates specifically to graphical design was observed as an educator demonstrated to some students, using the software, how to easily draw a turtle, to then erase what he had just done and challenge students to do it themselves. Another successful approach identified was asking the students to explain how they had solved a problem for which they had previously demanded help, and from there asking them to 
VI Congresso Brasileiro de Informática na Educação (CBIE 2017)

Anais do XXVIII Simpósio Brasileiro de Informática na Educação (SBIE 2017)

make adaptations to their solution, if applicable. This increases students' independence, by making them used to developing their own solutions, employing their abilities. Many times, prompting, and not direct answers, is sufficient (and more efficient for learning) in a process of problem solving. The situation below, extracted from field notes, illustrates student John's attempt to solve a programming task with the help of educator Daniel ${ }^{1}$ :

In order to help John to write a specific passage of code, Daniel explained to him the logic of the programming structures of conditionals: 'if' and 'otherwise', and the use of a boolean attribute, all available in the language of the programming environment. John, employing technical language, explained to Daniel how he was going to write the code, using a boolean attribute. Daniel answered: "okay, I think there's an easier way, but do it as you're planning". And John started coding. Later on, John realized the code was getting far too long and complicated. Daniel started prompting him about his choice of the boolean attribute, and the possibilities of other conditional structures, which made John rewrite his code, producing a much more efficient and clean program. Daniel asked him to explain what he had done in the end, and he showed understanding of the programming structures.

\subsubsection{Suitable programming environment}

Observation of activities showed students' satisfaction in being able to solve problems and add new functionalities to the game by developing the code themselves, with minimal help. In order to support this, a programming environment with immediate feedback (through code compilation and execution, for example), good usability and allowing different levels of software modification by the end user [Mørch 1997] is crucial, giving students the possibility of autonomously developing their programming skills through discovery. An extract from Daniel's field notes illustrates this:

John talked about a type of actors group that does not collide with anything, and that it could be used for a background image, for example. This demonstrates knowledge of the tool. I have noticed that he is developing code using events much more than behaviors (which uses pre-defined code). This demonstrates more autonomy and self-confidence to develop his own codes. Today I only gave minimal help, as needed.

Software extension is a particularly important indicator of student's autonomy, not only in the process of game development, but also in the ability of developing own code, paving the way to future programming projects.

\subsubsection{Hard deadlines}

From a much more practical point of view, but not less important, imposing hard deadlines had a surprisingly positive impact on students' autonomous productivity. When faced to a fixed date for completing a certain phase of the process, students engaged in establishing a viable game scope considering their technical abilities. For example, when discussing deadlines, a student suggested using only potatoes as game

\footnotetext{
${ }^{1}$ All names were changed to guarantee anonymity.
} 
VI Congresso Brasileiro de Informática na Educação (CBIE 2017)

Anais do XXVIII Simpósio Brasileiro de Informática na Educação (SBIE 2017)

characters, because they had already been drawn by the designers, instead of pursuing the current idea of having several mini-games with different characters. This helped them focus and find viable solutions, which is an important professional ability.

\subsection{Colaboration}

More than a need for achieving goals, collaboration in educational environments allows for mutual learning through knowledge exchange, where a more advanced person can help a peer in their personal development (according to the concept of zone of proximal development [Vygotsky 1989]). Key aspects related to collaboration identified in the processes are described next.

\subsubsection{Small groups}

As in most educational contexts, even in research projects such as Setting 2, there is a relative small number of educators to a larger number of students. It is much more probable that a socio-interactionist learning environment will be successful - or even viable - if educators are able to collaborate closely with small groups of students.

\subsubsection{Tasks in loco}

Students presented great difficulties in performing tasks when physically separated. As all tasks were in small groups, they were expected to collaborate, mostly through communication technologies, during the week. However, despite the number of possible communication channels available (in this particular context, Facebook and Whatsapp were the most popular), distance collaboration failed. More often than not, in Setting 2, where project meetings took place once a week, students had not progressed with their activities and had major problems with distance collaboration, to the point of generating heated discussions. In Setting 1, the students preferred coming to the school out of formal hours to work together and with educators. Further investigation is needed to understand the reasons for these unexpected difficulties, given that this generation is very used to digital communication tools.

\subsubsection{Hard deadlines}

Besides promoting autonomy, hard deadlines also contributed for increasing collaboration, as production of the game always depended, in every phase, of collaboration between programmers and designers, educators and students. Field notes reported that although students complained about the short time available, the time pressure makes their interaction focused on the work to be done collectively.

\subsubsection{Educator's collaboration in management}

In Setting 2, although students tried to organize themselves for efficiently developing the game, the need for help in managing the activities was evident. One of the educators took the role of manager, distributing activities according to students' abilities and checking their progress. This was not planned in the project, which gave students nearly full autonomy, but the team perceived a lack of maturity for carrying on the work without organizational help. Probably, with time, students would be less dependent on this support for effective collaboration. This assumption is backed up by Setting 1, where students spend three years immersed in a game development process, and have the opportunity to develop their self-management skills. They are asked to choose a 
VI Congresso Brasileiro de Informática na Educação (CBIE 2017)

Anais do XXVIII Simpósio Brasileiro de Informática na Educação (SBIE 2017)

student representative for design and programming in each group, to facilitate collaboration, and are able to do it more autonomously with time.

\subsubsection{Educator's collaboration in conceptual and technical domains}

Despite being encouraged to being autonomous and exploratory, students demonstrated the need for educators' help with conceptual and technical contents. A student from Setting 1 declared:

I like it here [at school] because we have the teachers' support. For example: we need to develop a game. I can do it, because I have the software tools, they're free, I can download them and work from home. But we can also come here, because we have the teachers. The teachers are here. Oh, I don't know this thing, but the teacher is there for me. That's good. Because the teacher is here to help us with our problems. We're not alone.

\subsection{Interest in Participating}

When showing interest in taking part in activities, people reflect their preoccupation with the quality of their tasks and productions [Lave and Wenger 1991]. In the processes observed, students demonstrated care for good-quality products (e.g. a passage of code, illustration, or a part of the game narrative). Interest was also evident when they showed up at meetings during the school holidays or stayed in after-class hours, as noted by one of them in the excerpt that names this article: "Today is so cool nobody wants to leave!". Key aspects identified to keep students interested in participating follow.

\subsubsection{Periodic evaluation}

Setting 1 is a formal educational setting and therefore must abide to institutional rules. Students must be graded to pass their school years, and the game prototypes developed are periodically evaluated also as a way to give students feedback to help them improve.

\subsubsection{Hard deadlines}

Again, hard deadlines also increased interest in participating. In Setting 2, the number of students that attended the meetings increased as the end date of the project approached. Students felt the need of finishing the game by the deadline, and became highly participative and productive. Despite the positive effects noticed in the three categories of engagement, it goes without saying that deadlines must be managed carefully to avoid extreme pressure and stress.

\subsubsection{Sense of purpose}

Students' interest in participating strongly depended on the sense of purpose they could attribute to the activity of game development. For example, the opportunity of taking the game to a competition, going beyond being graded at school for it. Aware of this extra motivational factor, the educators in Setting 1 integrate the deadlines of a student competition of game development to the school calendar. In Setting 2, students were very motivated by the fact that their peers who were not in the project, as well as other friends and family, would be able to play a game developed by them.

\subsubsection{Democratic choices}


When students are allowed to choose the theme of the games, they demonstrate more interest in actively participating. In Setting 2, in spite of the imposition that the game should explicitly address some curricular content, students are still free to choose the specific topics. Making this choice involves performing research about curricular contents and how to integrate them to a game.

\subsubsection{Role flexibility}

In both settings, students could opt for the role of graphic designer or programmer, according to their preferences. Even though participation in DEMULTS is voluntary, it may happen that students involved do not develop actual interest for computer science or design. In this case, they may collaborate with curricular content in the game. There were also cases of students who lost interest in the activities of the chosen role throughout the project and started autonomously migrating and / or taking up other responsibilities. Respecting these students' autonomy and allowing them to change roles was crucial for maintaining their participation. In Setting 2, student Julio started as a programmer (he even had previous programming experience) but lost interest in the activity. He stopped contributing, and gave as an excuse the lack of knowledge of the programming environment. After some time, Julio took up design activities on his own, and worked alone and independently:

Julio ended up creating a separate game, and the educators had to intervene to mediate the integration of his work to the game in development by the group. Despite his barriers for working collaboratively, at the end of the cycle Julio was happy to admit that the final version of the game included his contributions.

Cleo had also opted for being a programmer. But she never felt engaged with the programming activities, and became disinterested in the project as a whole. She would come to the meetings without her computer, or she would bring it and watch random videos, or sometimes she joined the design team as they discussed some aspects of the game. Naturally, by interacting with the design group, Cleo started contributing to the conception of the game narrative, and became one of the most participative students. The possibility of changing roles can become problematic if all students decide they want to do the same thing. On the other hand, allowing students to take up the role to which they feel most attracted is more coherent with the philosophy of participatory design, where people have significant influence on conceiving the product and making decisions, while learning from each other [Bødker et al. 1995].

\section{Conclusions and Future Work}

This research investigated two school-based contexts where processes of digital games' development were executed, with students in leadership positions with the support of educators. Analysis of interviews and field notes revealed key aspects to promote engagement through autonomy, collaboration and interest in participation. Overall, the aspects identified reinforce the importance of a democratic environment and pedagogical approaches based on socio-interactionism. However, not all project decisions made aligned to these theoretical frames proved successful. Students could deal with a certain level of autonomy, but were too immature to manage themselves and the process, collaborate when physically apart, and be productive without specific dates for some kind of evaluation of formal checkpoint. In particular, hard deadlines were 
identified as a key aspect for the three categories analyzed. This need for rigor seems to be yet inherited from the traditional model of education, which trains us to aim at deadlines and be periodically graded for our performances.

On the other hand, it was clear that lectures and long periods of theoretical classes were not effective. Aligned with Constructionism, practical activities where students developed code or draw game scenes - and to reach these goals had to solve problems and make discoveries with the support of the educators - proved much more engaging and productive. The methods of end-user programming, software modification and participatory design were key choices for creating a suitable environment.

Finally, school-based projects have to abide to rigid rules and legislation, and lack of adequate infrastructure. The analysis of the two processes and the identification of methods and aspects that promote engagement in this kind of environment form the basis for a consolidated proposal for processes of participatory game development in school contexts. Such proposal, including phases of process and their activities, artifacts and tools, pedagogical orientation and methodology, constitutes our main future work.

\section{References}

Blikstein, P. (2015). "O Movimento Maker e FabLabs na Educação: finalmente realizando o sonho de Freire e Papert, ou mais uma futura história de fracasso?". Keynote Talk. (26th October 2015). Brazilian Conference of Informatics in Education (CBIE). Maceió, Brazil.

Bødker, S.; Grønbæk, K. and Kyng, M. (1995). "Cooperative design: techniques and experiences from the Scandinavian scene". In: Readings in Human-Computer Interaction: Toward the Year 2000. Morgan-Kaufmann.

Fredricks, J. A.; Blumenfeld, P. C. and Paris, A. H. (2004). "School engagement: Potential of the concept, state of the evidence". In: Review of educational research, Sage Publications, v. 74, n. 1, p. 59 - 109.

Kanthan, G. D/O S. (2011). "Strengthening student engagement in the classroom". Dissertation. National University of Singapore - Faculty of Science.

Lave, J. and Wenger, E. (1991). "Situated learning: legitimate peripheral participation". Cambridge University Press.

Lieberman, H. et al. (2006). "End-user development: An emerging paradigm". In: End user development, Springer. p. $1-8$.

Lim, C. P. (2008). Spirit of the game: Empowering students as designers in schools? British Journal of Educational Technology, 39(6), 996-1003.

Mattar, J. (2010). "Games em educação: como os nativos digitais aprendem". São Paulo: Pearson Prentice Hall.

Meira, L. and Pinheiro, M. (2012). Inovação na escola. In: XI Brazilian Symposium of Games and Digital Entertainment. Brasília, Brazil.

Mørch A. (1997). "Three levels of end-user tailoring: Customization, integration, and extension". In: Computers and design in contexto. MIT Press, Cambridge, USA, p. $51-76$. 
VI Congresso Brasileiro de Informática na Educação (CBIE 2017)

Anais do XXVIII Simpósio Brasileiro de Informática na Educação (SBIE 2017)

Papert, S. and Harel, I. (1991). "Situating constructionism". Constructionism, v. 36, p. $1-11$.

Parsons, J. and Taylor, L. (2011). "Improving student engagement". Current issues in education, v. 14, n. 1.

Prensky, M. (2001). "Digital natives, digital immigrants". Part 1. On the horizon, MCB UP Ltd, v. 9, n. 5, p. $1-6$.

Robertson, J., and Howells, C. (2008). Computer game design: Opportunities for successful learning. Computers \& Education 50, 559-578.

Sagayadevan, V. and Jeyaraj, S. (2012). "The role of emotional engagement in lecturerstudent interaction and the impact on academic outcomes of student achievement and learning". In: Journal of the Scholarship of Teaching and Learning, v. 12, n. 3, p. 1 30 .

Triantafyllakos, G., Palaigeorgiou, G.; and Tsoukalas, I. A. (2011). Designing educational software with students through collaborative design games: The We!Design\&Play framework. Computers \& Education 56, 227-242.

Vos, N., Meijden, H. v. d., and Denessen, E. (2011). Effects of constructing versus playing an educational game on student motivation and deep learning strategy use. Computers \& Education 56, 127-137.

Vygotsky, L. S. (1989). "Pensamento e linguagem". Ridendo Castigat Mores.

Willekens, R. and Gibson, P. (2010). "Hybrid courses and student engagement: opportunities and challenges for community college leaders". In: International In Journal of Educational Leadership Preparation, v. 5, n. 1.

Wyeth, P.; Johnson, D. and Ziviani, J. (2013). "Activity, motivation and games for young children". In: ACM. Proceedings of The 9th Australasian Conference on Interactive Entertainment: Matters of Life and Death.

Yang, Y.-T. C., and Chang, C.-H. (2013). Empowering students through digital games authorship: Enhancing concentration, critical thinking and academic achievement. Computers and Education, 68, 334-344.

Zepke, N.; Leach, L. and Butler, P. (2010). "Student engagement: What is it and what influences it". Teaching \& Learning Research Initiative. Wellington, New Zealand. 